\title{
The Optimal Suture Site for the Repair of Posterior Horn Root Tears: Biomechanical Evaluation of Pullout Strength in Porcine Menisci
}

\author{
Young-Mo Kim, MD, Yong-Bum Joo, MD, Chang-Kyun Noh, MD, and Il-Young Park, MD \\ Department of Orthopaedic Surgery, Chungnam National University School of Medicine, Daejeon, Korea
}

\begin{abstract}
Purpose: There are few studies on biomechanical evaluation of suture points in repair of root tears. The purpose of this study was to determine the point of greatest pullout strength for root tear repair.

Materials and Methods: A total of 120 fresh porcine medial menisci were obtained. The red-red and red-white zones of the meniscus were divided by two lines designated as lines A and B (groups A and B). Groups A and B were further divided into three groups each by dividing lines A and B into three points: 3,5 , and $7 \mathrm{~mm}$ from the meniscal ligament root insertion. Vertical meniscal repair was performed on each point. The pullout failure strength was tested using a biaxial servohydraulic testing machine.

Results: The average maximal load at failure was significantly greater in group A than group B (87.65 vs. 62.93 ; $\mathrm{p}<0.001)$ The average length at maximal load failure was greater in group A than group B (4.35 vs. 3.2; $\mathrm{p}<0.001)$. Among the subgroups of 3,5 , and $7 \mathrm{~mm}$ in both groups A and B, $7 \mathrm{~mm}$ showed the greatest maximal load $(\mathrm{p}<0.001)$.

Conclusions: The pullout strength was statistically significantly greater in group A than group B and in the 7 mm subgroup than the 3 and 5 mm subgroups. Thus, the $7 \mathrm{~mm}$ subgroup in group A showed the greatest pullout strength.
\end{abstract}

Keywords: Knee, Osteoarthritis, Medial meniscus, Root tear

\section{Introduction}

The meniscus has important functions such stabilization of the joint through shock absorption in the knee joint and lubrication in joint cartilage ${ }^{1,2}$. The meniscus also distributes loading of weight by sustaining hoop strain ${ }^{3)}$. Root tears of the medial meniscus have gained growing attention among many orthopedic surgeons ${ }^{4,5)}$. The posterior portion of the medial meniscus car-

Received July 6, 2015; Revised (1st) September 10, 2015;

(2nd) November 16, 2015; (3rd) January 14, 2016;

(4th) February 16, 2016; Accepted February 22, 2016

Correspondence to: Yong-Bum Joo, MD

Department of Orthopaedic Surgery, Chungnam National University

School of Medicine, 266 Munhwa-ro, Jung-gu, Daejeon 35015, Korea

Tel: +82-42-280-8083, Fax: +82-42-252-7098

E-mail: longman76@hanmail.net

This is an Open Access article distributed under the terms of the Creative Commons Attribution Non-Commercial License (http://creativecommons.org/licenses/by-nc/4.0/) which permits unrestricted non-commercial use, distribution, and reproduction in any medium, provided the original work is properly cited. ries a greater proportion of the load compared with the anterior portion ${ }^{6}$. The posterior horn of the medial meniscus (PHMM) is attached to the tibia by the root ligament positioned in front of the posterior cruciate ligament, and root ligament tears of the PHMM can cause degenerative arthritis of the knee joint ${ }^{7,8)}$. The root serves as the anchor point for the meniscus. An injury to the root can lead to meniscal extrusion ${ }^{9)}$. In particular, a posterior root tear of the medial meniscus can induce significant changes in contact pressure and knee joint kinematics similar to those caused by total meniscectomy ${ }^{5}$. Radial tears at the root of the PHMM result in loss of meniscal circumferential hoop pressure and have been reported to be biomechanically equivalent to a total meniscectomy ${ }^{5,7,10)}$. This could be suggested as the theoretical background of many studies that propose the necessity for arthroscopic repair of root ligament tears of the PHMM ${ }^{4,8,11,12)}$.

Whenever possible, surgeons make utmost effort to repair medial meniscus posterior root tears and various repair techniques have been developed. Unfortunately, repair of root tears can be technically demanding and it is difficult to determine accurate 
suture points. Capturing the posterior horn further from the edge may create excessive tension on the meniscal body, whereas placing the suture too close to the edge may result in suture cutout and loss of fixation; this may be a another factor for failure of meniscal root repair. Accurate suture points for meniscal root repair include repair into transosseous bone tunnels, transosseous suture passage for surface fixation, and suture anchor fixation ${ }^{4,11)}$. In spite of recent attempts for biomechanical evaluation of these techniques, there have been only a small number of biomechanical studies for medial meniscal root repair ${ }^{13-17)}$. The purpose of this in vitro biomechanical study is to determine the greatest pullout strength point for repair of root tears of the PHMM in an animal model.

\section{Materials and Methods}

\section{Methods}

Medial menisci were gained from fresh porcine (Yorkshire pig) posterior left knee joints $(n=120)$. The young adult animals were obtained from an abattoir. The mean age of the animals was 6 months, and the mean body weight was $116 \pm 5.3 \mathrm{~kg}$. Only intact menisci without observable evidence of previous injury or visible signs of cartilage degenerative changes were used. To simulate a radial tear at the root of the PHMM, the meniscus root was incised at meniscoligamentous junctional area with a No. 15 blade scalpel. The specimens were stored at $-70^{\circ} \mathrm{C}$ being covered with gauze soaked in normal saline and then thawed at room temperature for 24 hours before biomechanical testing. For biomechani-

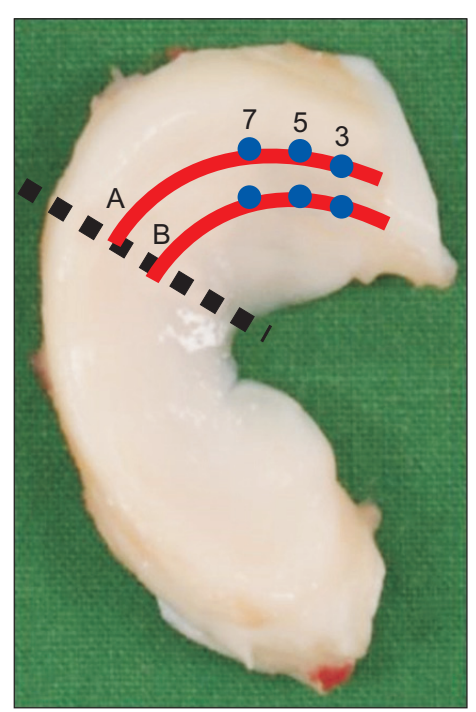

Fig. 1. Repair sites of the posterior horn of the porcine meniscus: line A (red-red zone) and line B (red-white zone). The lines were again divided into 3 points: 3,5 , and $7 \mathrm{~mm}$. cal testing, 120 menisci were randomly divided into 2 groups of 60 specimens each. The red-red zone (within $3 \mathrm{~mm}$ from meniscocapsular junction) and the red-white zone (3-5 mm from meniscocapsular junction) of the meniscus were divided each by 2 lines designated as line $\mathrm{A}$ and line $\mathrm{B}$. The lines were again divided into 3 points $(3,5$, and $7 \mathrm{~mm}$ from the meniscus root ligament root insertion) and each was designated as subgroups 3, 5, and 7 $\mathrm{mm}$, respectively (Fig. 1). Vertical meniscal repair was done by a No. 2 Ethibond (Ethicon, Somerville, NJ, USA) suture and a straight needle. Realization of pullout strength was done by counter suture in the direction of vector based on the root. The pullout failure strength was tested with a biaxial servohydraulic testing machine (model 8874; Instron Corp., Norwood, MA, USA). Specimens were tested in a random order, and the failure testing was performed at a speed of $5 \mathrm{~mm} / \mathrm{min}$ (Fig. 2). Endpoints were maximum failure load and mode of failure. Mode of failure was determined by visual inspection of the failure result. The protocol of our study was referred from the study of Anz et al. ${ }^{13)}$.

\section{Statistical Analysis}

To evaluate the statistical significance of the differences between groups A and B, and groups 3, 5, and $7 \mathrm{~mm}$ and the correlation with the thickness, statistical analysis was performed using the SPSS ver. 20.0 (IBM Co., Armonk, NY, USA). To compare groups $\mathrm{A}$ and $\mathrm{B}$, a $t$-test was done, and comparison of each group was conducted using one-way analysis of variance (ANOVA). For statistical analysis of the correlation between groups A, B and subgroups 3, 5, and $7 \mathrm{~mm}$, two-way ANOVA was performed (since subgroups 3, 5, and $7 \mathrm{~mm}$ all showed increasing patterns according to the loading force, there was no correlation among them).

\section{Results}

This study used 120 cases of swine meniscus and there were 60 cases each for group A and group B. Group A and group B were again divided into 3 subgroups, 3, 5, and $7 \mathrm{~mm}$, which consisted of 20 each.

Regarding the maximal load at failure, the average was greater with 87.65 for group A than 62.93 for group B, and the difference was statistically significant $(\mathrm{p}<0.001)$. The average length at maximal load failure was greater with 4.35 for group A and 3.2 for group B $(\mathrm{p}<0.001)$ (Table 1$)$.

Among the subgroups of 3,5 , and $7 \mathrm{~mm}$ in both group $\mathrm{A}$ and group $B$, the $7 \mathrm{~mm}$ subgroup showed the greatest maximal load, followed by the $5 \mathrm{~mm}$ subgroup and the $3 \mathrm{~mm}$ subgroup $(p<0.001)$. The differences among the subgroups were statistically 

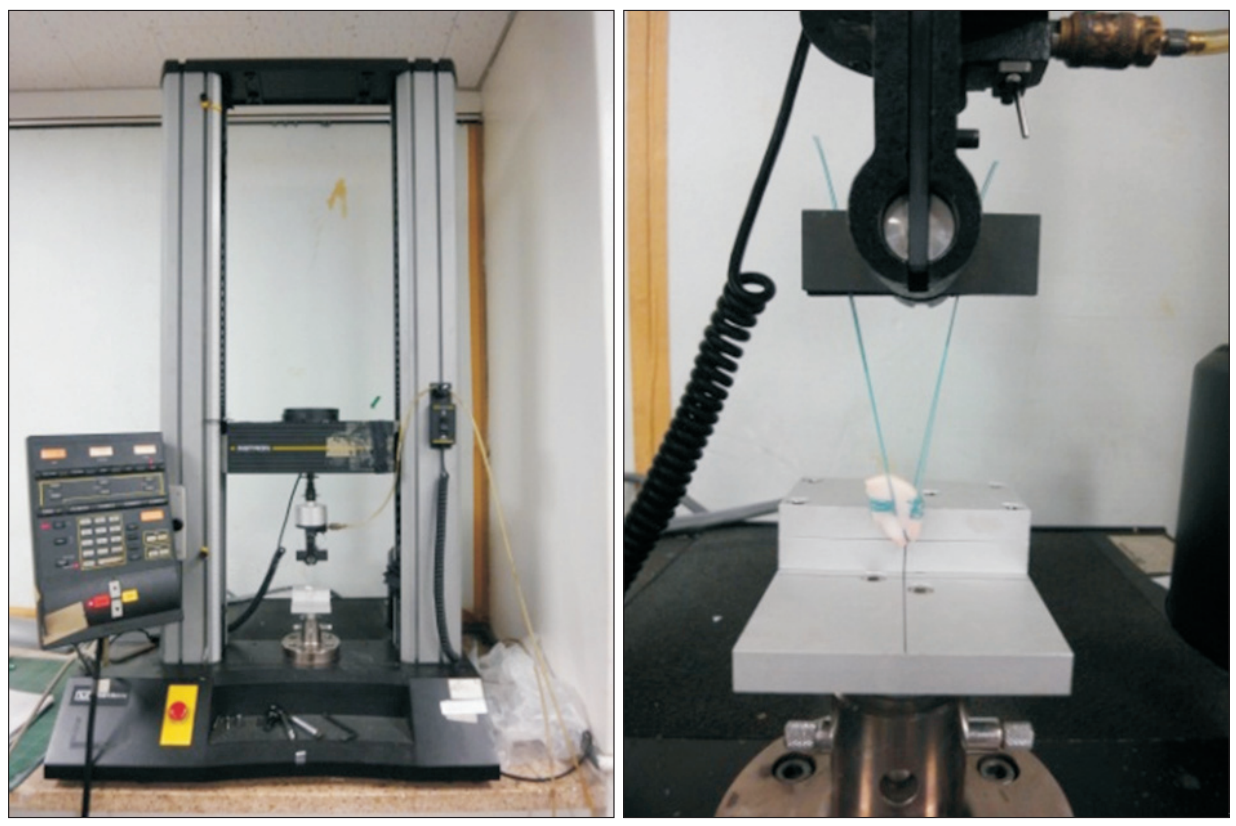

Fig. 2. Biaxial servohydraulic testing machine.

Table 1. Maximal Load and Length of Group A and Group B

\begin{tabular}{lcccc}
\hline \multicolumn{1}{c}{ Characteristic } & Cases & Average & Standard deviation & t-test $^{\mathrm{a})}$ \\
\hline Maximal load (NF) & & & & \\
Group A & 60 & 87.65 & 37.66 & 4.06 \\
Group B & 60 & 62.93 & 29.27 & \\
Length (mm) & & & & \\
Group A & 60 & 4.35 & 0.98 & 7.76 \\
Group B & 60 & 3.25 & 0.52 & \\
\hline
\end{tabular}

NF: Newton force.

${ }^{a)} \mathrm{p}<0.001$.

significant $(\mathrm{p}<0.001)($ Table 2$)$.

Consequently, the average maximal load was greater in group A than group B and in the $7 \mathrm{~mm}$ subgroup than the 3 and $5 \mathrm{~mm}$ subgroups. The differences between groups $A$ and $B$ and among the 3,5, and $7 \mathrm{~mm}$ subgroups were statistically significant $(\mathrm{p}<0.001)$.

As a result, in terms of correlation between groups $A$ and $B$ and subgroups 3,5 , and $7 \mathrm{~mm}$, no significant combined effect that influenced the result was found. However, since the correlation of the maximum pullout strength between groups $\mathrm{A}$ and $\mathrm{B}$ and subgroups 3,5 , and $7 \mathrm{~mm}$ showed a similar pattern, no notable statistical significance was found ( $p>0.05$ and 0.474 , respectively). Between groups A and B, group A showed greater pullout strength, and among subgroups 3,5 , and $7 \mathrm{~mm}$, subgroup $7 \mathrm{~mm}$ exhibited greater pullout strength. Thus, the subgroup $7 \mathrm{~mm}$ of group A showed the strongest pullout strength.
Table 2. Analysis of Variance for Maximal Load and Length of Subgroups of Group A and Group B

\begin{tabular}{lrrcr}
\hline \multicolumn{1}{c}{ Characteristic } & Cases & Average & Standard deviation & F-test $^{\text {a) }}$ \\
\hline Maximal load (NF) & & & & \\
$3 \mathrm{~mm}$ & 40 & 54.25 & 30.33 & 18.09 \\
$5 \mathrm{~mm}$ & 40 & 74.92 & 30.01 & \\
$7 \mathrm{~mm}$ & 40 & 96.70 & 34.18 & \\
Total & 120 & 75.29 & 35.81 & \\
Length (mm) & & & & \\
$3 \mathrm{~mm}$ & 40 & 3.43 & 0.89 & 11.57 \\
$5 \mathrm{~mm}$ & 40 & 3.64 & 0.62 & \\
$7 \mathrm{~mm}$ & 40 & 4.33 & 1.07 & \\
Total & 120 & 3.80 & 0.96 & \\
\hline
\end{tabular}

NF: Newton force.

${ }^{\text {a) }} \mathrm{p}<0.001$.

\section{Discussion}

The degenerative horizontal tear of the PHMM is the most common type of injury of the meniscus in late middle age ${ }^{18,19}$. In Asian countries, certain postures, such as cross-legged sitting and crouching, are frequent in daily life and could easily lead to a tear of the root ligament of the PHMM, which is the part where the PHMM is attached on the anterior tibia to the posterior cruciate ligament ${ }^{20}$. Bin et al..$^{3)}$ reported that the mean age of patients with root ligament tears of the PHMM was 56.3 years (range, 31 to 77 years), and the crouching posture and sitting lifestyle of the Ko- 


\section{Kim et al. Optimal Suture Site for the Repair of Posterior Horn Root Tear}

rean population could increase the load on the medial meniscus, causing degenerative changes of the knee joint.

The functions of the meniscus include body weight transfer, shock absorption, stability of the knee joint, lubrication, supplement of nutrients, and proprioceptive sensation. The development of degenerative arthritis after meniscectomy has been well documented ${ }^{21,22)}$. Therefore, the current surgical trend is to preserve the medial meniscus as much as possible ${ }^{23,24)}$.

If a complete radial meniscus tear at the tibial attachment site of the medial meniscus posterior horn (MMPH) heals after repair, hoop tension can be restored. We previously reported a technical note describing an arthroscopic pullout suture repair of a complete radial tear of the tibial attachment site of the MMPH. Our hypothesis was that reattachment of the meniscus after a complete radial tear adjacent to the tibial attachment site of the meniscus would improve healing and facilitate the restoration of hoop tension. In conclusion, we recommended that the sutures be passed through the red-red zone of the meniscus and meniscocapsular junction located $7 \mathrm{~mm}$ medial to the edge of the tear. The method had at least 2 advantages. First, the red-red zone and meniscocapsular junction tissues are not torn easily when the suture material is pulled out at the proximal tibia for tying. Second, because the red-red zone and meniscocapsular junction tissues are highly vascular and some tissues are inserted through the tibial tunnel when the suture material is pulled out, the potential for healing is high.

There are many disputes on the best treatment for root ligament tears. However, most reports on this subject have focused on surgical treatment; there have been few studies on the reparability of the root ligament and few reports measured the actual pullout failure strength from the torn root ligament of the $\mathrm{PHMM}^{25)}$. Kocabey et al. ${ }^{26)}$ performed a biomechanical study to measure the pullout failure strength of several suturing techniques on the medial meniscus of 1-year-old bovines after creating a vertical longitudinal incision on the medial meniscus. They reported that the pullout failure strength of oblique, vertical, and horizontal sutures was $171.9 \pm 25.9,145.9 \pm 32.3$, and $88.2 \pm 8.2 \mathrm{~N}$, respectively. They found that oblique sutures provided comparable biomechanical fixation to vertical sutures during submaximal cyclic tests that simulated early rehabilitation loads and superior fixation during load to failure testing. Kohn and Siebert ${ }^{27)}$ conducted a biomechanical study using cadavers and compared the pullout failure strengths of the following four suturing techniques: knot-end suture, arthroscopic technique using a loop placed on the meniscus, open vertical stitching suture, and open horizontal suture. Pullout failure strengths in their study were $24 \pm 9,89 \pm 4,105 \pm 4$, and $44 \pm 18 \mathrm{~N}$, respectively. They reported that the load at failure of a vertical suture $(105 \pm 4 \mathrm{~N})$ was superior to that provided by a horizontal suture $(89 \pm 4 \mathrm{~N})$ and recommended vertical suture.

In a previous study, we assessed the actual pullout failure strength of the PHMM and reparability of PHMM ${ }^{28}$. The pullout failure strength was $71.6 \pm 23.2 \mathrm{~N}$ (range, 41.4 to $107.7 \mathrm{~N}$ ), using PHMM specimens confirmed to have root ligament tears that were identified among middle-aged patients during arthroscopic surgery. But there was a limitation. No comparison was made between meniscal thickness of the needle insertion point and the pullout failure strength.

The porcine knee is an inexpensive but effective model used for training surgeons on arthroscopic reconstruction procedures involving the anterior and posterior cruciate ligaments and other knee structures ${ }^{29}$. Porcine knees are a bit smaller but similar to human knees; thus, orthopedic surgeons could use them effectively to learn how to perform simple procedures. For this reason, we considered porcine knees as a good model for biomechanical studies and conducted this in vitro biomechanical study to determine the greatest strength point for repair of root tears of the PHMM in an animal model. And, the relatively slow biomechanical test loading rate was used to stimulate the stresses that the meniscus might be subjected to during early rehabilitation exercise, slow speed walking in daily life, stepping up and down, and squatting after meniscal repair ${ }^{30}$. There were several limitations of this study. First, post hoc power analysis was not performed. Second, repair at the point of $7 \mathrm{~mm}$ from the posterior root may create more tension on the body than that at $5 \mathrm{~mm}$; therefore, further research is needed on the maximal strength of a repair performed at more than $7 \mathrm{~mm}$ from the posterior root. Finally, this was not a human study.

\section{Conclusions}

Group A showed statistically significantly greater pullout strength than group B, and $7 \mathrm{~mm}$ subgroup exhibited statistically significantly greater pullout strength than subgroups 3 and $5 \mathrm{~mm}$. Thus, the subgroup $7 \mathrm{~mm}$ of group A showed the greatest pullout strength.

\section{Conflict of Interest}

No potential conflict of interest relevant to this article was reported. 


\section{Acknowledgements}

This research was supported by Chungnam National University Research Fund.

\section{References}

1. Fukuda Y, Takai S, Yoshino N, Murase K, Tsutsumi S, Ikeuchi K, Hirasawa Y. Impact load transmission of the knee joint-influence of leg alignment and the role of meniscus and articular cartilage. Clin Biomech (Bristol, Avon). 2000; 15:516-21.

2. Scott WN, Insall JN. Insall \& Scott surgery of the knee. 5th ed. Philadelphia, PA: Elsevier 2012; p269-77.

3. Bin SI, Kim JM, Shin SJ. Radial tears of the posterior horn of the medial meniscus. Arthroscopy. 2004;20:373-8.

4. Ahn JH, Wang JH, Yoo JC, Noh HK, Park JH. A pull out suture for transection of the posterior horn of the medial meniscus: using a posterior trans-septal portal. Knee Surg Sports Traumatol Arthrosc. 2007;15:1510-3.

5. Allaire R, Muriuki M, Gilbertson L, Harner CD. Biomechanical consequences of a tear of the posterior root of the medial meniscus. Similar to total meniscectomy. J Bone Joint Surg Am. 2008;90:1922-31.

6. Ahmed AM, Burke DL. In-vitro measurement of static pressure distribution in synovial joints: part I: tibial surface of the knee. J Biomech Eng. 1983;105:216-25.

7. Jones RS, Keene GC, Learmonth DJ, Bickerstaff D, Nawana NS, Costi JJ, Pearcy MJ. Direct measurement of hoop strains in the intact and torn human medial meniscus. Clin Biomech (Bristol, Avon). 1996;11:295-300.

8. Lee JH, Lim YJ, Kim KB, Kim KH, Song JH. Arthroscopic pullout suture repair of posterior root tear of the medial meniscus: radiographic and clinical results with a 2-year followup. Arthroscopy. 2009;25:951-8.

9. Costa CR, Morrison WB, Carrino JA. Medial meniscus extrusion on knee MRI: is extent associated with severity of degeneration or type of tear? AJR Am J Roentgenol. 2004;183: 17-23.

10. McDermott ID, Amis AA. The consequences of meniscectomy. J Bone Joint Surg Br. 2006;88:1549-56.

11. Choi NH, Son KM, Victoroff BN. Arthroscopic all-inside repair for a tear of posterior root of the medial meniscus: a technical note. Knee Surg Sports Traumatol Arthrosc. 2008; 16:891-3.

12. Nicholas SJ, Golant A, Schachter AK, Lee SJ. A new surgical technique for arthroscopic repair of the meniscus root tear. Knee Surg Sports Traumatol Arthrosc. 2009;17:1433-6.

13. Anz AW, Branch EA, Saliman JD. Biomechanical comparison of arthroscopic repair constructs for meniscal root tears. Am J Sports Med. 2014;42:2699-706.

14. LaPrade CM, LaPrade MD, Turnbull TL, Wijdicks CA, LaPrade RF. Biomechanical evaluation of the transtibial pullout technique for posterior medial meniscal root repairs using 1 and 2 transtibial bone tunnels. Am J Sports Med. 2015; 43:899-904.

15. LaPrade RF, LaPrade CM, Ellman MB, Turnbull TL, Cerminara AJ, Wijdicks CA. Cyclic displacement after meniscal root repair fixation: a human biomechanical evaluation. Am J Sports Med. 2015;43:892-8.

16. Feucht MJ, Grande E, Brunhuber J, Rosenstiel N, Burgkart $\mathrm{R}$, Imhoff $\mathrm{AB}$, Braun S. Biomechanical comparison between suture anchor and transtibial pull-out repair for posterior medial meniscus root tears. Am J Sports Med. 2014;42:18793.

17. Feucht MJ, Grande E, Brunhuber J, Rosenstiel N, Burgkart R, Imhoff $\mathrm{AB}$, Braun S. Biomechanical evaluation of different suture materials for arthroscopic transtibial pull-out repair of posterior meniscus root tears. Knee Surg Sports Traumatol Arthrosc. 2015;23:132-9.

18. Smillie IS. Injuries of the knee joint. 5th ed. Edinburgh: Churchill Livingstone; 1978. p114-8.

19. Englund M. Meniscal tear: a feature of osteoarthritis. Acta Orthop Scand Suppl. 2004;75:1-45.

20. Nishimura A, Hasegawa M, Kato K, Yamada T, Uchida A, Sudo A. Risk factors for the incidence and progression of radiographic osteoarthritis of the knee among Japanese. Int Orthop. 2011;35:839-43.

21. Johnson RJ, Kettelkamp DB, Clark W, Leaverton P. Factors effecting late results after meniscectomy. J Bone Joint Surg Am. 1974;56:719-29.

22. McGinity JB, Geuss LF, Marvin RA. Partial or total meniscectomy: a comparative analysis. J Bone Joint Surg Am. 1977;59:763-6.

23. Bolano LE, Grana WA. Isolated arthroscopic partial meniscectomy. Functional radiographic evaluation at five years. Am J Sports Med. 1993;21:432-7.

24. Jorgensen U, Sonne-Holm S, Lauridsen F, Rosenklint A. Long-term follow-up of meniscectomy in athletes: a prospective longitudinal study. J Bone Joint Surg Br. 1987;69:80-3.

25. Freutel M, Scholz NB, Seitz AM, Ignatius A, Durselen L. Mechanical properties and morphological analysis of the 


\section{Kim et al. Optimal Suture Site for the Repair of Posterior Horn Root Tear}

transitional zone between meniscal body and ligamentous meniscal attachments. J Biomech. 2015;48:1350-5.

26. Kocabey Y, Taser O, Nyland J, Doral MN, Demirhan M, Caborn DN, Sarban S. Pullout strength of meniscal repair after cyclic loading: comparison of vertical, horizontal, and oblique suture techniques. Knee Surg Sports Traumatol Arthrosc. 2006;14:998-1003.

27. Kohn D, Siebert W. Meniscus suture techniques: a comparative biomechanical cadaver study. Arthroscopy. 1989;5:324-7.

28. Kim YM, Joo YB. Pullout failure strength of the posterior horn of the medial meniscus with root ligament tear. Knee Surg Sports Traumatol Arthrosc. 2013;21:1546-52.

29. Boguszewski DV. Characterizing the porcine knee as a biomechanical surrogate model of the human knee to study the anterior cruciate ligament [thesis]. Cincinnati, OH: University of Cincinnati; 2012. p162.

30. Sgaglione NA, Steadman JR, Shaffer B, Miller MD, Fu FH. Current concepts in meniscus surgery: resection to replacement. Arthroscopy. 2003;19 Suppl 1:161-88. 